\title{
An Analysis of English Vocabulary Based on Corpora From the Korean and American Versions of The Good Doctor
}

\author{
Koh, Sungran \\ (Kookmin University)
}

\begin{abstract}
Koh, Sungran. (2018). An analysis of English vocabulary based on corpora from the Korean and American versions of The good doctor. STEM Journal, 19(4), 2744.

The popular Korean drama Good Doctor (Ki \& Kim, 2013) was adapted and remade in the US and broadcast from September, 2018 by ABC as The Good Doctor (Daly, 2018). Consequently, the role of subtitling also plays an important part among a variety of countries with different cultures and languages. This paper concentrates on a comparison and analysis of the subtitles for both the American The Good Doctor and the Korean Good Doctor, aiming to identify the lexical differences and frequency of English words, phrases and sentences in both. First, the lexical differences and occurrences of expressions in English open class word groups are analyzed according to a text analyzer and parts-of-speech tagger (POS tagger). Next, they are divided into three phrase groups - noun phrases, verb phrases, and prepositional phrases, which are compared and analyzed. The data is then divided into seven categories according the Bhagat and Hovy's (2013) 25 classes. This study shows that even though the number of characters, syllables, words, and sentences in the Korean Good Doctor $(K G)$ is higher than that of the American The Good Doctor $(A G)$, the lexical density in $A G$ is higher than that of $K G$. This implies that AG uses more vocabulary variety and less vocabulary repetition.
\end{abstract}

\section{INTRODUCTION}

As the world is globalizing, people all over the world are able to get easy access to other countries' culture and products through social network services or social media. As a result, the Korean wave, Hallyu or Hanryu has spread quickly, and the popularity of Korean products and culture has risen across East, South and Southeast Asia. K-pop and Korean TV dramas have become influential global phenomena. The K-pop group singers BTS became the first K-Pop Act to hit No.1 on the Billboard Artist 100 Chart. Along with Kpop music, Korean dramas lead the Korean Wave and have proliferated with social media 
and other online culture. Chuang and Lee (2013) mention that "the storylines that are rooted in real-life family situations, characters that beat the odds, and a definite ending 16-20 episodes compared to the indefinite American soap opera" (p. 594). Kim (2013) also argues that because the Korean TV dramas are emotionally powerful and selfreflective, they have become so popular. As the popularity of Korean drama has increased, the Korean drama Good Doctor (Ki \& Kim, 2013) was remade and broadcasted in September, 2018 by ABC and named The Good Doctor (Daly, 2018). The Korean Good Doctor was broadcasted from August, $5^{\text {th }}$ to October, $8^{\text {th }}$ in 2013 by KBS. It is about a doctor with autism but has grown up to become a great doctor.

ABC's The Good Doctor has not changed the background and fully reflects the original Korean version. It is the first time in Korean history that the emotions of Korean drama has moved Hollywood. It shows the possibility that other Korean dramas could be promoted by Hollywood. This is such a meaningful and important avenue for Korean drama to develop and advance in the future.

Consequently, the translations play a crucial role for foreign viewers to understand the dramas. Serban (2004) notes two kinds of audio-visual translation, intra-lingual and interlingual. The source language of intra-lingual translation is the same as the target language while inter-lingual translation is translated to foreign languages such as "from one language into another language" and "from spoken dialogue into written text, condensed translation which appears on the screen" (Dries, 1995, p. 26). Inter-lingual subtitles also play a significant role for the viewers understanding.

Díaz Cintas (2009) argues that subtitling and audio-visual translation were generally overlooked and even now still "lack a proper historiography of audio-visual translation and its study today" (p. 1). Many subtitles of Korean drama through streaming services is currently provided by fan viewers, not professionals, which is called 'fan-subbing.' As a result, mistranslation is more likely to appear on the screen.

This paper is focused on comparison and analysis of the subtitles for both the American The Good Doctor and the Korean Good Doctor and to find out the lexical differences and frequency of the expressions between them such as English words, phrases and sentences. First of all, the lexical differences and occurrence of the expressions in English open class words are analyzed according to the text analyzer and part-of-speech tagger (POS tagger). Next, they are divided into three phrases such as noun phrase, verb phrase and prepositional phrase, which are compared and analyzed. Next, the data is divided into seven categories according the Bhagat and Hovy's (2013) 25 classes and analyzed.

Cuetos, Glez-Nosti, Barbon, and Brysbaert (2011) claim, "in all languages tested, subtitle frequencies outperform text-based word frequency" (p. 141). Through this study, it is expected that the usefulness of subtitle-based frequent words, phrases, and patterns is emphasized in teaching ESL learners following the tendency of those who prefer watching 
to reading. In addition, it is expected that paraphrase practice through interesting dramas would be helpful in learning how to speak and write in more interesting ways, especially through paraphrase.

\section{LITERATURE REVIEW}

\section{Online Subtitles}

As technology has rapidly developed, a mixture of technology and language has spread in an audio-visual format. Rossum (2015) states, "Audio-visual Translation (henceforth referred to as AVT) means any form of translation of audio-visual material" (p. 7). Among the AVT, online subtitling is one of the attractive sources of data because they are freely downloaded from a number of online sites in a wide variety of languages. Levshina (2015) states, "Probably the most attractive feature of film subtitles in comparison with other multilingual parallel corpora is that film subtitles are, as a rule, stylistically much closer to informal spoken dialogues than any of these corpora" (p. 1).

As the websites sharing film and TV subtitles with different languages are increasing, subtitles are essentially translated into spoken dialogues, and they make a good and reasonable source of dialogue data. Film subtitles are limited by particular restrictions such as typeface, position 'at the bottom of the screen,' and the maximum length of a line. Accordingly, film translation is very different from literary translation.

Subtitle translation is not an easy job because it transfers the characteristics of spoken dialogue to the written mode, and it has some constraints and limitations. Munday (2012) states that AVT is a very restrictive type of translation, such as the "co-existence of the sound channel and the vision channel, which restrict procedures open to the translator" ( $p$. 269). Accordingly, subtitlers should be aware of the regulations or technical limitations when they translate the subtitles, and as a result, the role of subtitle translators is important in the audio-visual media.

New, Brysbaert, Veronis, and Pallier (2007) assert that word frequencies from film and TV subtitles display more visual word recognition than the word frequencies from written texts. The reason for this is that the vocabularies from film and TV are more frequently used than the written texts in our daily life. Cuetos, et al. (2011) also note, "Written texts also tend to exaggerate lexical variation in order to avoid word repetition, which does not occur in spoken language" (p. 135). Therefore, it is more effective for ESL learners to use subtitles which are much closer to the language used in daily life. 


\section{Paraphrase}

Much research has investigated paraphrase and has contributed to the many related concepts and studies. Paraphrase is the sentences or phrases that convey the same meaning using other words. Dras (1999) mentions "a pair of units of text deemed to be interchangeable" (p. 57). The example is the following:

(1) a. The school said that their buses seat 40 students each.

b. The school said that their buses accommodate 40 students each.

(Bhagat \& Hovy, 2013, p. 464)

According to Tschirsich and Hintz (2013), "the notion of a paraphrase is closely related to the concepts of semantic similarity and word ontology and an exact definition is not trivial" (p. 206). In view of the semantic similarity, paraphrase is related to 'restates'. For example, "murder of the 35th U.S. president" is restated as "assassination of John F. Kennedy" with the different terms (Tschirsich \& Hintz, 2013, p. 205).

On the other hand, Bhagat and Hovy (2013) mention, "Although the logical definition of paraphrases requires strict semantic equivalence, linguistics accepts a broader, approximate, equivalence - thereby allowing far more examples of 'quasi-paraphrase'. But approximate equivalence is hard to define" (p. 463). Further, they add the following examples.

(2) a. The school said that their buses seat 40 students each.

b. The school is saying that their buses might accommodate 40 students each.

(Bhagat \& Hovy, 2013, p. 465)

In (2a) and (2b), said and is saying have different tenses and might accommodate and seat are not synonymous. Noting this point, Bhagat and Hovy (2013) categorized a set of 25 classes that produce quasi-paraphrase. The 25 classes are as follows.

TABLE 1

25 Classes of Quasi-paraphrases (Bhagat \& Hovy, 2013)

\begin{tabular}{ll}
\hline \hline & 25 Classes \\
\hline 1. Synonym substitution & 14. Part/Whole substitution \\
2. Antonym substitution & 15. Verb/Noun conversion \\
3. Converse substitution & 16. Verb/Adjective conversion \\
4. Change of voice & 17. Verb/Adverb conversion \\
5. Change of person & 18. Noun/Adjective conversion \\
\hline
\end{tabular}


An Analysis of English Vocabulary Based on Corpora From the Korean and American Versions of The Good DoctorThe Good Doctor

\begin{tabular}{ll}
\hline 6. Pronoun/Co-referent substitution & 19. Verb-preposition/Noun substitution \\
7. Repetition/Ellipsis & 20. Change of tense \\
8. Function word variations & 21. Change of aspect \\
9. Actor/Action substitution & 22. Change of modality \\
10. Verb/“Semantic-role noun" substitution & 23. Semantic implication \\
$\begin{array}{ll}\text { 11. Manipulator/Device substitution } & \text { 24. Approximate numerical equivalences } \\
\text { 12. General/Specific substitution } & \text { 25. External knowledge } \\
\text { 13. Metaphor substitution } & \end{array}$ \\
\hline
\end{tabular}

Each class has its own requirement of specific semantic equivalence. Along with this line, this article categorized the subtitles based on Bhagat and Hovy's (2013) 25 classes. Our data does not include the entire 25 classes, and this article is categorized into seven categories: Synonym substitution, semantic implication, repetition/ellipsis, antonym substitution, function word variations, pronoun/co-referent substitution, and external knowledge.

\section{METHODOLOGY}

In this research, the Korean-English subtitles of the Korean Good Doctor and EnglishKorean subtitles of the American The Good Doctor are analysed focusing on the lexical usage. Korean-English subtitles of the Korean Good Doctor are examined in the video streaming website, YouTube. The American The Good Doctor was downloaded onto DVD from the internet.

The Korean Good Doctor has a total of 20 episodes, and the American The Good Doctor has a total of 18 episodes. The object of this study is episode one in both. The Korean Good Doctor runs for one hour and the American The Good Doctor runs for forty-five minutes. Consequently, the number of words of the American The Good Doctor is relatively smaller than the Korean Good Doctor, which is considered to analyze the subtitles and regulate the proportional rates. It is necessary to be aware that the numbers used in this paper are calculated on the number corresponding to the counterpart.

To analyze the subtitles data, two tools are used which are the text analyzer and the POS tagger. The text analyzer is a piece of software utility which finds the most frequent phrases and frequencies of words. It calculates the number of characters, words, sentences, and syllables. The POS tagger is software that reads text in a designated language and tags parts of speech to each word, such as noun, verb, adjective, etc. It was developed by Stanford University and is called the Stanford Log-Linear Part-Of-Speech Tagger. In this paper, text analyzer is used to count the number of frequent words and phrases whereas the POS tagger is utilized to analyze and categorize into several groups by tagging the part of speech. 
As the last step of the analysis, based on the Bhagat and Hovy's (2013) 25 classes mentioned before, the data is classified into seven categories which are Synonym Substitution, semantic implication, repetition/ellipsis, antonym substitution, function word variations, pronoun/co-referent substitution, and external knowledge. Even though there have been narrow and broad interpretations of paraphrases, more logical and stricter classification is needed. In this aspect, this kind of classification approach is meaningful and consequential to define paraphrase.

\section{RESULTS AND DISCUSSION}

\section{Word Comparison and Analysis}

Jin (2017) states, "the length of film subtitles translated into Chinese is generally longer than the corresponding dialogue in the original English" (p. 278). Interestingly, our result is the same as Jin (2017). Overall, the number of characters, words, sentences, syllables and characters in the Korean Good Doctor $(K G)$ is higher than that of the American The Good Doctor $(A G)$. The remarkable thing is the lexical density which is higher in $A G$ than $K G$. According to Halliday (1985), "Lexical density is the kind of complexity that is typical of written language" (p. 62). The more diverse a word a text has, the higher lexical diversity. Johansson (2008) mentions that "For a text to be highly lexically diverse, the speaker or writer has to use many different words, with little repetition of the words already used" (p. 60). The result based on this theory means that Korean translators are less likely to use a variety of vocabulary and more likely to repeat the same vocabulary even though they use a much larger number of words, sentences, syllables and characters. The results are as follows.

TABLE 2

Comparison Between Korean Good Doctor and American The Good Doctor

\begin{tabular}{ccc} 
Comparison Between Korean Good Doctor and American The Good Doctor & AG \\
\hline \hline & $K G$ & 15,542 \\
Number of characters (including spaces) & 17,895 & 11,578 \\
Number of characters (without spaces) & 13,507 & 2,763 \\
Number of words & 3,190 & 21 \\
Lexical density & 20 & 482 \\
Number of sentences & 513 & 3959 \\
Number of syllables & 4607 & \\
\hline
\end{tabular}

Words can be divided into two major classes, "open class / content and closed class / function words" (Jose et al., 2001, p. 397). The open class is open new words having the 
meaning such as nouns, verbs, adjectives and adverbs while closed class does not easily accept new words such as prepositions, conjunctions, pronouns, determiners, etc. Along this line, this data is categorized into open class such as noun, verb, adjective and adverb. Interestingly, the order in word frequency is the same in both $K G$ and $A G$. The highest frequency rate of the words is verb. Next in order are noun, adverb and adjective. The frequency of the words is as follows.

TABLE 3

Word Frequency

\begin{tabular}{ccc}
\hline \hline & $K G$ & $A G$ \\
& word & word \\
\hline Verb & 781 & 639 \\
Noun & 683 & 534 \\
Adverb & 223 & 200 \\
Adjective & 199 & 168 \\
\hline
\end{tabular}

\section{1) Verb}

The most frequent verbs in $K G$ are the 'be verb' such as is, are, and the ones in $A G$ are have, $b e, d o$. Interestingly, in both $K G$ and $A G$, the words of the high rank six in frequency are the same even though they have the different ranks: be verb (is, are, was), have, and do.

The frequent base verbs in $K G$ are go, get, know, become think, like, make, want, has whereas the ones in $A G$ are get, like, want, know, need, think, has, make, give, hire, got, were, etc. The words used in common in both $K G$ and $A G$ are be (be, am, is, are, was), become, do (don't), have (has), excuse, get (got), go, help, hire, know, keep, like, make, stop, take, think, and want which occur over three times.

TABLE 4

Occurrence Order of Verbs

\begin{tabular}{cccc}
\hline \hline \multicolumn{1}{c}{$K G$} & Occur. & word & Occur. \\
\hline word & 56 & have & 30 \\
is & 45 & be & 29 \\
are & 36 & do & 26 \\
be & 35 & swas & 25 \\
have & 27 & are & 19 \\
do & 25 & don't, get & 18 \\
was & 22 & like & 14 \\
go & 20 & want & 13 \\
don't, & 19 & know, need & 12 \\
get & 16 & think, has & 11 \\
know & 13 & make & 10 \\
become, think & & &
\end{tabular}




\begin{tabular}{cccc}
\hline like, want, make & give & 9 \\
has & 11 & hire, got, were & 8 \\
stop, let, see, check \\
take & 10 & mean & 7 \\
& 9 & stop, go, take, saved, place, & 6 \\
help, heard, had & 8 & consent, & 5 \\
needs, show & 4 \\
bring, hurry, call, care, damage, \\
got, went, find
\end{tabular}

By using the POS Tagger, verbs are categorized into six subsets such as verb base form (VB), verb non-3sg pres (VBP), verb 3sg pres (VBZ), verb past tense (VBD), verb past participle (VBN), verb gerund (VBG).

According to the analysis, $K G$ is more than twice the word number as $A G$ in verb base form (VB). This means Korean translators are more likely to use verb base form because it is much shorter and simpler. The other reason is that to-infinitive appears 79 times. Since to-infinitive is a form of to in front of a verb, it is included in verb base form (VB). Another noticeable thing is that the most rates are high in $K G$ except for verb non-3sg pres (VBP) and verb gerund (VBG). This implies the Korean translators relatively tend not to use verb gerunds.

FIGURE 1

Subset of the Verb Form

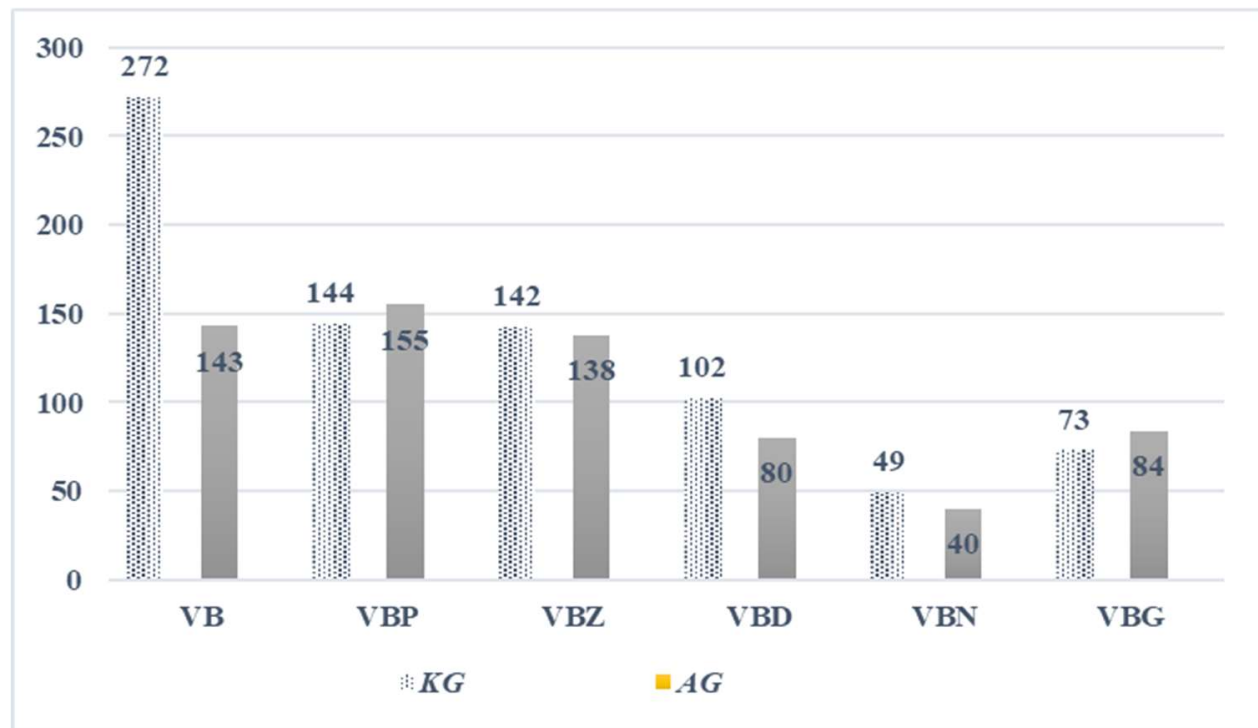


TABLE 5

Subset of the Verb Form

\begin{tabular}{ccccccc}
\hline \hline & $\begin{array}{c}\text { verb base } \\
\text { form(VB) }\end{array}$ & $\begin{array}{c}\text { verb non- } \\
\text { 3sg pres } \\
\text { (VBP) }\end{array}$ & $\begin{array}{c}\text { verb 3sg } \\
\text { pres } \\
(\mathrm{VBZ})\end{array}$ & $\begin{array}{c}\text { verb past } \\
\text { tense } \\
(\mathrm{VBD})\end{array}$ & $\begin{array}{c}\text { verb past } \\
\text { participle } \\
(\mathrm{VBN})\end{array}$ & $\begin{array}{c}\text { verb } \\
\text { gerund } \\
(\mathrm{VBG})\end{array}$ \\
\hline$K G$ & 272 & 144 & 142 & 102 & 49 & 73 \\
\hline$A G$ & 143 & 155 & 138 & 80 & 40 & 84 \\
\hline
\end{tabular}

\section{2) Noun}

Unlike verbs, nouns are different in that the word ranks are not in accord with $K G$ and $A G$. Because both of them are medical dramas, they have in common medical words such as doctor, suction, vein, chest, jugular, and life.

It is noted that $K G$ used the same nouns more frequently while $A G$ used more diverse nouns in various ways.

TABLE 6

Occurrence Order of Nouns

\begin{tabular}{lllc}
\hline \hline \multicolumn{1}{c}{$K G$} & \multicolumn{1}{c}{$A G$} \\
\hline \multicolumn{1}{c}{ Word } & Occur. & \multicolumn{1}{c}{ Word } & Occur. \\
\hline Jugular, school, university, pulse, & 4 & hospital & 11 \\
vessels, birthday, station, hours, & \multicolumn{1}{c}{ eco, people } & 9 \\
chest, people, ball, star, step, & time, life, heart & 8 \\
decision, president, tamponade, & echocardiogram, medical, knife, boy & 7 \\
residency, pain, syndrome, suction, & doctor, emergency, way, surgeon & 6 \\
savant, importance, patient's, doctor, & Suction, things & 5 \\
casino, vein, dumb, vice, procedure, & glass, adult, jugular, heaven, board, & 4 \\
center, liver, room, shock, neck, & doctors, blood, surgery & \\
medicine, trauma, sake, bunny & children, tube, year, autism school, & 3 \\
& valve, effusion, vein, light & \\
\hline
\end{tabular}

\section{3) Adjective}

Adjectives are subcategorized into adjective (JJ), adjective comparative (JJR), and adjective superlative (JJS). Adjectives also appear much more in $K G$ than in $A G$. However, $A G$ has as double adjective comparative as $K G$.

TABLE 7

Subset of the Adjectives

\begin{tabular}{cccc}
\hline \hline & JJR & JJS & JJ \\
& (adjective comparative) & (adjective superlative) & (adjective) \\
\hline$K G$ & 3 & 5 & 191 \\
$A G$ & 8 & 2 & 158 \\
\hline
\end{tabular}


TABLE 8

Occurrence Order of Adjectives

\begin{tabular}{|c|c|c|c|}
\hline$K G$ & Occur. & $A G$ & Occur. \\
\hline wrong & 9 & & \\
\hline normal, good, first & 7 & sure & 7 \\
\hline fine & 6 & other, normal, medical & 6 \\
\hline cardiac, medical, pediatric, pericardial & 5 & right, personal & 5 \\
\hline able, happy, sure, much, new, other & 4 & same & 4 \\
\hline $\begin{array}{l}\text { Internal, due, enough, great, heavy, } \\
\text { mental, new, okay, psychological, } \\
\text { right }\end{array}$ & 3 & $\begin{array}{l}\text { superior, left, dead, different, fine, } \\
\text { first, good, new, nice, one-way, } \\
\text { open, own, proud, ready, surgical, } \\
\text { wrong, young }\end{array}$ & 3 \\
\hline $\begin{array}{l}\text { arrogant, autistic, bad, critical } \\
\text { cured, definite, entire, general, hard } \\
\text { hungry, incapable, intravenous, late, } \\
\text { national, new, Next, rid, Same, } \\
\text { savant, simple, sorry, special, sudden }\end{array}$ & 2 & $\begin{array}{l}\text { afraid, capable, cardiac, cool, } \\
\text { excellent, healthy, necessary, } \\
\text { okay, old, perfect, pericardial, } \\
\text { second, sharp, smart, sorry, } \\
\text { weird, why }\end{array}$ & 2 \\
\hline
\end{tabular}

The common words between them are as follows: fine, first, good, new, normal, okay, other, right, same, sure, wrong, cardiac, medical, and pericardial.

\section{4) Adverb}

The most crucially frequent adverb is $n$ ' $t$ and not in both $K G$ and $A G$. Even though it has been argued whether negation is an adverb or not, the POS tagger categorized not, no, and never into a kind of adverb of negation. The common adverbs between them are again, already, as, because, else, even, here, just, much, not, now, n't, quite, really, right, so soon, and still.

TABLE 9

Occurrence Order of Adverb

\begin{tabular}{lclcc}
\hline \hline & $K G$ & Occur. & & Occur. \\
\hline n't & 57 & n't & 51 \\
not & 25 & not & 26 \\
here, there & 12 & here, just, & 11 \\
just, so & 11 & now & 8 \\
never & 8 & again & 7 \\
even, right & 7 & so, very & 6 \\
now, well & 6 & there & 5 \\
because, first, quickly, really. sir, & 4 & also, sure & 4 \\
still, too & & & ago, back, because, ever, exactly, \\
about, again, all, always, as, & 3 & maybe, okay, really, right, soon \\
completely, else, much, soon, & \multicolumn{3}{c}{3} \\
\hline
\end{tabular}


An Analysis of English Vocabulary Based on Corpora From the Korean and American Versions of The Good DoctorThe Good Doctor

\section{Phrase and Chunk Comparison and Analysis}

\section{1) Verb Phrases}

It is interesting that the most common verb phrases in both $K G$ and $A G$ are have to, want to, and need to in spite of the different ranks. It is proven necessary for the ESL beginners to learn these forms.

To infinitive appears such as try to, used to, would love to, be supposed to, and be able to. Also, get verb phrases are often used such as get beaten, get drunk, get rid of, get out, get the consent, get it, and get to. In addition, go verb phrases are often used such as go against, go home, and go to heaven.

Verb + preposition phrases are used such as look at, prepare for, suffer from, get rid of, beat up, turn off, figure out, talk about, consent to, cure for, get out, listen to, and be capable of. Levshina (2015) claims, "subtitlers tend to use will instead of be going to, replace light verb constructions with simple verbs (e.g. feel instead of have the feeling), and use simple rather than complex tenses (e.g. simple past instead of past perfect)". As our data prove, reduced simple verbs or verb tenses often tend to be used.

TABLE 10

Occurrence of the Verb Phrases

\begin{tabular}{|c|c|c|c|}
\hline$K G$ & Occur. & $A G$ & Occur \\
\hline have to & 11 & & \\
\hline want to & 9 & & \\
\hline need to & 6 & want to & 7 \\
\hline & & need to, have to & 5 \\
\hline make sure, go home, go to heaven & 4 & try to & 4 \\
\hline try to & 3 & used to, turn off & 3 \\
\hline $\begin{array}{l}\text { get beaten, get drunk, get rid of, get } \\
\text { out, look at, take care, prepare for, } \\
\text { suffer from, be able to, listen to beat } \\
\text { up, go against }\end{array}$ & 2 & $\begin{array}{l}\text { would love to, take a look, } \\
\text { figure out, talk about, consent } \\
\text { to, cure for, supposed to, get } \\
\text { out, get the consent, get it, get } \\
\text { to, be capable of }\end{array}$ & 2 \\
\hline
\end{tabular}

\section{2) Noun Phrases}

Most of the noun phrases are related medical terms. Although $K G$ and $A G$ are the same content, the same medical words are not used except for jugular vein and savant syndrome. 
Many more medical terms are used in $K G$.

TABLE 11

Occurrence of the Noun Phrases

\begin{tabular}{cccc}
\hline \hline$K G$ & Occur. & $A G$ & Occur. \\
\hline first aid & 6 & medical emergency & 4 \\
blood pressure & 5 & pericardial effusion & 3 \\
$\begin{array}{c}\text { jugular vein, savant syndrome, } \\
\text { medical school, vice president } \\
\text { vena cava, beef stew, intravenous } \\
\begin{array}{c}\text { injection, pediatric surgeon, cardiac } \\
\text { arrest, pericardial puncture, cardiac } \\
\text { tamponade, general surgeon }\end{array}\end{array}$ & 2 & $\begin{array}{c}\text { jugular vein, savant syndrome, } \\
\text { surgical resident, heart rate }\end{array}$ & 2 \\
\hline
\end{tabular}

\section{3) Preposition Phrases}

Even though a variety of prepositional phrases appear in each of $K G$ and $A G$, because of is the most frequent prepositional phrase in both of them. Also, out of and in front of are also in common.

TABLE 12

Occurrence of the Preposition Phrases

\begin{tabular}{cccc}
\hline \hline$K G$ & Occur. & $A G$ & Occur. \\
\hline because of & 4 & & \\
due to & 3 & because of & 3 \\
out of, listen to, in front of & 2 & in front of, up to, out of & 2 \\
\hline
\end{tabular}

\section{Sentence Comparison and Paraphrase Classification}

Even though some of the subtitles in $K G$ and $A G$ have the same meaning, they have different words, different meaning, and different sentence structure. Ivarsson (1992) argues that paraphrases are unavoidable in translating. According the Bhagat and Hovy's (2013) 25 classes, the data is divided into seven categories which are synonym substitution, semantic implication, repetition/ellipsis, antonym substitution, function word variations, pronoun/co-referent substitution, and external knowledge. The ordering is according to the number of the corresponding subtitles.

\section{1) Synonym Substitution}

Synonym substitution replaces a word or phrase with a synonymous word or phrase and becomes a paraphrase of the original sentence. For example, go to is expressed as get to, 
headed as going, and suffers from savant syndrome as has savant syndrome. The director of the hospital is used as President of this hospital. Also, was damaged is used as has been cut which has different words and different tense. If this analysis is followed the Bhagat and Hovy's (2013) 25 classes, this example could also be included in 'change of tense', but it is considered to put in 'synonym substitution' in this analysis.

TABLE 13

Synonym Substitution

\begin{tabular}{|c|c|}
\hline 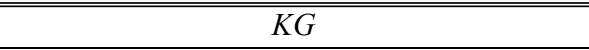 & $A G$ \\
\hline The jugular vein was damaged. & His jugular vein's been cut. \\
\hline I need to go to Sung Won University Hospital. & $\begin{array}{l}\text { I need to get to San Jose St. Bonaventure } \\
\text { Hospital. }\end{array}$ \\
\hline That's where we are headed. & That's where we're going. \\
\hline He saved his child. & He saved his life. \\
\hline $\begin{array}{l}\text { Mr. Park Shi On suffers from Savant } \\
\text { Syndrome. }\end{array}$ & $\begin{array}{l}\text { He has autism, but he also has savant } \\
\text { syndrome. }\end{array}$ \\
\hline He show ingenious abilities in specific areas. & He has genius-level skills in several areas. \\
\hline $\begin{array}{l}\text { I will resign from my position as the director } \\
\text { of the hospital. }\end{array}$ & $\begin{array}{l}\text { I will resign my position as President of this } \\
\text { hospital. }\end{array}$ \\
\hline
\end{tabular}

\section{2) Semantic Implication}

Semantic implication takes the place of a word or phrase by adding or deleting proper function words and sentence restructuring. This often leads to a quasi-paraphrase. For example, You can't do it is used for Behave yourself. The details are as following:

TABLE 14

Semantic Implication

\begin{tabular}{|c|c|}
\hline$K G$ & $A G$ \\
\hline You can't do it! & Behave yourself. \\
\hline $\begin{array}{l}\text { She needs psychological treatment to get over her } \\
\text { fear of surgery. }\end{array}$ & She's not psychologically ready for surgery. \\
\hline $\begin{array}{l}\text { I wanted to let them become adults. I wanted them } \\
\text { to have kids of their own, and love those kids. }\end{array}$ & $\begin{array}{l}\text { They should have had children of their own } \\
\text { and loved those children. }\end{array}$ \\
\hline $\begin{array}{l}\text { I can buy a 3D television for the kids from my } \\
\text { childhood orphanage. }\end{array}$ & $\begin{array}{l}\text { I want to make a lot of money so that I can } \\
\text { have a television. }\end{array}$ \\
\hline $\begin{array}{l}\text { Mr. Park shows his strength in his memory skills } \\
\text { and spatial intelligence. }\end{array}$ & $\begin{array}{l}\text { He has almost perfect recall. He has spatial } \\
\text { intelligence. }\end{array}$ \\
\hline $\begin{array}{l}\text { Is it possible for him to not go to heaven? Can I } \\
\text { make someone not go to heaven? }\end{array}$ & $\begin{array}{l}\text { I don't want him to go to heaven! I want him } \\
\text { to be here! Has he gone to heaven? }\end{array}$ \\
\hline
\end{tabular}




\section{3) Repetition/Ellipsis}

Ellipsis is a restatement of the original sentence and often makes a meaning-preserving paraphrase. Ivarsson (1992) mentions "say in a few seconds two or three times as many words as there is room for in the two (at best, three) subtitle lines below the picture" (p. 92). For instance, Give him an opportunity for six months generates an elliptical structure such as Give him six months.

TABLE 15

Repetition/Ellipsis

\begin{tabular}{ll}
\hline \multicolumn{1}{c}{$K G$} & \multicolumn{1}{c}{$A G$} \\
\hline Give him an opportunity for six months. & Give him six months. \\
$\begin{array}{l}\text { You are much, much, smarter than me. } \\
\text { If there's any trouble or if we see that he's }\end{array}$ & $\begin{array}{l}\text { If Shaun doesn't live up to everything I know } \\
\text { he can do, he will be immediately released. }\end{array}$ \\
$\begin{array}{ll}\text { incapable of being a doctor. } & \text { His heart is fine. }\end{array}$ \\
\hline
\end{tabular}

\section{4) Antonym Substitution}

Antonym substitution replaces a word or phrase to its antonym by a negation or negating other word, which may come together by adding or deleting proper function words. For example, Nothing seemed wrong... is expressed to ...normal... and ...not... normal is expressed to ... weird.... Also, not win is replaced with lose.

TABLE 16

Antonym Substitution

\begin{tabular}{ll}
\multicolumn{1}{c}{$K G$} & \multicolumn{1}{c}{$A G$} \\
\hline \hline Nothing seemed wrong with his heart. & All cardiac vital signs are within normal range. \\
I don't think he's normal. & He was really weird. \\
Nobody knows our chances of winning & You think you're gonna lose? \\
\hline
\end{tabular}

\section{5) Function Word Variations}

Function word variations replace the function words in a sentence without affecting its meaning, which replaces a determiner with a preposition, and adds or deletes a preposition or a determiner, etc. For example, Stay here for now is used for Now stay here, in which the preposition for is added. Furthermore, in spite of the same meaning, the articles $a$ and the are used differently: Neither one had a chance to become an adult $(K G)$ and Neither one had the chance to become an adult $(A G)$. 
TABLE 17

Function Word Variations

\begin{tabular}{|c|c|}
\hline KG & $A G$ \\
\hline Neither one had a chance to become an adult. & Neither one had the chance to become an adult. \\
\hline Stay here for now. & Now stay here. \\
\hline
\end{tabular}

\section{6) Pronoun/Co-referent Substitution}

Pronoun/Co-referent substitution changes a pronoun into the noun phrase, which often makes the strictest meaning-preserving paraphrase. For example, A surgeon at this hospital is replaced with the pronoun he.

TABLE 18

Pronoun/Co-referent Substitution

\begin{tabular}{ll}
\hline \multicolumn{1}{c}{ Pronoun/Co-referent Substitution } & \multicolumn{1}{c}{$A G$} \\
\hline A surgeon at this hospital saved the child. & $\begin{array}{l}\text { He saved his life! Apparently, he's one of our } \\
\text { doctors. }\end{array}$ \\
\hline
\end{tabular}

\section{7) External Knowledge}

External knowledge takes the place of a word or phrase based on extra-linguistic (world) knowledge, which may be changed by adding or deleting proper words and sentence restructuring. For example, doctor is used instead of surgeon. In Korea, doctor is used regardless of their specialty, and not physician, surgeon, orthopedist, gynecologist, etc.

TABLE 19

\section{External Knowledge}

\begin{tabular}{ll}
\hline \hline \multicolumn{1}{c}{$K G$} & \multicolumn{1}{c}{$A G$} \\
\hline $\begin{array}{l}\text { He is more qualified to be a doctor than anyone } \\
\text { else. }\end{array}$ & $\begin{array}{l}\text { Those are assets. Undeniable assets for any } \\
\text { doctor, particularly a surgeon. }\end{array}$ \\
$\begin{array}{ll}\text { Why do you want to become a doctor here? } & \begin{array}{l}\text { I'd like you to tell us why you want to become a } \\
\text { surgeon. }\end{array}\end{array}$ \\
\hline
\end{tabular}

\section{CONCLUSION}

Levshina (2015) notes, "Online film subtitles are particularly convenient for the purposes of language comparison because one can easily find subtitles of the same film in many different languages and create a parallel corpus, using the timing information for alignment" (p. 3). Following a suggestion by Levshina (2015), we have examined lexical differences and frequency of the expressions between them such as English words and 
phrases of the subtitles for both the American The Good Doctor and the Korean Good Doctor. Then we classified the paraphrasing sentences into seven classes according to Bhagat and Hovy's (2013) 25 classes.

Even though both The Good Doctor dramas are medical dramas which have almost the same background and content, most words, especially nouns, are usually not the same except for the common medical words such as doctor, suction, vein, chest, jugular, and life. However, the verb phrases are similar or common to each other such as be verb (is, are, was), have, and be (be, am, is, are, was), become, do (don't), have (has), excuse, get (got), go, help, hire, know, keep, like, make, stop, take, think, and want.

The result shows that even though the number of characters, syllables, words, and sentences in the Korean Good Doctor $(K G)$ is higher than that of the American The Good Doctor $(A G)$, the lexical density in $A G$ is higher than that of $K G$. This implies $A G$ uses more vocabulary variety with less vocabulary repetition.

Consequently, two points are suggested. First, it is a good way to teach ESL learners English frequency words, phrases and patterns, especially using the verb phrase patterns. It is intriguing and inspiring for ESL students to learn them through interesting dramas.

Secondly, it is suggested that paraphrase practice through interesting dramas should be beneficial in ESL classes. To be more detailed, to apply paraphrase patterns through Bhagat and Hovy's (2013) 25 classes should be easier and more adaptable than not using any tool.

Rasul, Bukhsh, and Batool (2011) claim, "Audio-Visual aids are those instructional devices which are used in the classroom to encourage learning and make it easier and interesting" (p. 79). Therefore, it is suggested that teachers should make every effort to offer their students effective and efficient methods and material through available technology and multimedia.

\section{REFERENCES}

Bhagat, R., \& Hovy, E. (2013). What is a paragraph? Computational Linguistics, 39(3), 463-472.

Chuang, L. M., \& Lee, H.-E. (2013). Korean wave: Enjoyment factors of Korean dramas in the U.S.. International Journal of Intercultural Relations, 37(5), 594-604.

Cuetos, F., Glez-Nosti, M., Barbon, A., \& Brysbaert, M. (2011). SUBTLEX-ESP: Spanish word frequencies based on film subtitles. Psicologica, 33(2), 133-143.

Daly, L. (Director). (2018). The good doctor [Television series]. New York, NY: ABC.

Díaz Cintas, J. (2009). New trends in audiovisual translation. London: Routledg.

Dras, M. (1999). Tree adjoining grammar and the reluctant paraphrasing of text (Doctoral 

dissertation). Macquarie University, Australia.

Dries, J. (1995). Dubbing and subtitling: Guidelines for production and distribution. Düsseldorf, Germany: European Institute for the Media.

Halliday, M. A. K. (1985). Spoken and written language. Victoria, Australia: Deakin University Press.

Ivarsson, J. (1992). Subtitling for the media: A handbook of an art. Stockholm: Transedit. Jin, Z. (2017). A comparative analysis of film subtitle translation from English to Chinese: A case study of 15 popular animation films (Unpublished doctoral dissertation). University of Salford, Manchester, UK.

Johansson, V. (2008). Lexical diversity and lexical density in speech and writing: A developmental perspective. Linguistics and Phonetics Working Papers, 53, 61-79.

Jose A., Manuel H., Pilar M-L., Francisco C., Luis M., Carlos C., \& Miguel, A. (2001). Semantic processing of open- and closed-class words: An event-related, potentials study. Cognitive Brain Research, 11(3), 397-407.

Ki, M. S., \& Kim, J. W. (Directors). (2013). Good doctor [Television series]. Seoul: KBS. Kim, Y. (2013). Introduction: Korean media in a digital cosmopolitan world. In Y. Kim (Ed.), The Korean wave: Korean media go global (pp. 125-147). Abingdon: Routledge.

Levshina, N. (2015). Online film subtitles as a corpus: An n-gram approach. Article in Corpora. doi: 10.3366/cor.2017.0123

Munday, J. (2012). Introducing translation studies: Theories and applications. London: Routledge.

New, B., Brysbaert, M., Veronis, J., \& Pallier, C. (2007). The use of film subtitles to estimate word frequencies. Applied Psycholinguistics, 28(4), 661-677.

Rasul, S., Bukhsh, Q., \& Batool, S. (2011). A study to analyze the effectiveness of audiovisual aids in teaching learning process at university level. Procedia - Social and Behavioral Sciences, 28, 78-81.

Rossum, J. V. (2015). Honorifics in Korea drama: A comparison of translation producers between amateur and professional subtitlers (Unpublished master's thesis). Leiden Unniversity, Leiden, the Netherlands.

Serban, A. (2004). Introduction to audiovisual translation. Leeds, UK: University of Leeds.

Tschirsich, M., \& Hintz, G. (2013). Leveraging crowdsourcing for paraphrase recognition. In A. Pareja-Lora, M. Liakata, \& S. Dipper (Eds.), Proceedings of the 7th Linguistic Annotation Workshop \& Interoperability with Discourse (pp. 205-213). Stroudsburg, PA: ACL Home Association for Computational Linguistics. 
Applicable levels: secondary and college education

Keywords: subtitles, corpus, Korean TV drama, paraphrase

\section{Koh, Sungran}

College of General Education

Kookmin University

77 Jeongneung-ro, Seongbuk-gu, Seoul, 02707, Korea

E-mail: sungran@kookmin.ac.kr

Received: October 25, 2018

Revised version: November 9, 2018

Accepted: November 27, 2018 